\title{
BIBLISMO, LENGUA VERNÁCULA Y TRADUCCIÓN EN CASIODORO DE REINA Y CIPRIANO DE VALERA
}

\author{
Juan Luis Monreal Pérez \\ Universidad de Murcia \\ jlmonreal@um.es \\ https://dx.doi.org/10.12795/futhark.2014.i9.13
}

\begin{abstract}
Examination of the contribution of Casiodoro de Reina and Cipriano de Valera to the vernacular language must be made in the context of three cultural currents that shook the European Renaissance period and found equal expression in the Spain of that time: Erasmianism, Reformism and Biblicism. Moreover, the use of the vernacular language by these two authors needs to be viewed from a broad historical-linguist perspective which allows one to view both the influence they received from the previous tradition, through translations of the Bible into Spanish, as well as the use they made of the Spanish language. Their contributions to the Spanish language have been made through the two translations of the Bible they made, and which were accomplished with the ideas and criteria presented in their respective introductions to the text named Amonestación y Exhortación.
\end{abstract}

Keywords: Erasmianism, Reformism, Biblicism, Vernacular Language, Translation.

Resumen: El examen de la contribución de Casiodoro de Reina y Cipriano de Valera a la lengua vulgar hay que hacerlo en el contexto de tres corrientes culturales que agitan el periodo renacentista europeo y que encuentran, igualmente, su expresión en la España de aquel tiempo: Erasmismo, Reformismo y Biblismo. Por otra parte, el uso de la lengua 
vernácula en ambos necesita ser visto desde una perspectiva histórico. lingüista amplia, que permita ver tanto la influencia que éstos recibieron de la tradición anterior, a través de las traducciones de la Biblia al caste. llano, como el uso que éstos hicieron de la lengua castellana. Sus aporta. ciones a la lengua española se han hecho a través de las dos traslaciones de la Biblia que llevaron a cabo, y que fueron realizadas con las ideas y los criterios que expusieron en sus correspondientes introducciones al texto que denominaron Amonestación y Exhortación.

Palabras clave: Erasmismo, Reformismo, Biblismo, Lengua Vernácula, Traslación.

\section{INTRODUCCIÓN}

El examen de la contribución de Casiodoro de Reina y Cipriano de Valera a la lengua vulgar hay que hacerlo en el contexto de tres corrientes culturales (Erasmismo, Reformismo y Biblismo) que agitan el periodo renacentista europeo y que encuentran, igualmente, su expresión en la España de aquel tiempo. Dichas corrientes, por otra parte, independientemente de su propia entidad están estrechamente relacionadas, de modo que son manifestaciones diversas de un mismo fenómeno cultural.

Por ello, a modo de introducción contextual de la obra de Casiodoro de Reina y Cipriano de Valera en relación a la lengua vernácula, se van a presentar, brevemente, aquellos rasgos más definitorios de dichas corrientes culturales.

\section{ERASMISMO, REFORMISMO Y BIBLISMO EN ESPAÑA}

\section{1. ERASMISMO Y CLIMA CULTURAL EN ESPAÑA}

Con la expresión Erasmismo, se suele significar -en términos generales-, la corriente de adhesión o de crítica y rechazo que generó la obra de Erasmo. No conviene, por tanto, entender tal término como un movimiento organizado y dirigido ni por Erasmo ni por ningún otro. El propio Erasmo se encarga de repetir su fidelidad a la Iglesia y 
su ortodoxia con la doctrina cristiana, independientemente de lo que otros pudieran pensar al respecto.

En primera instancia, podría parecer que se trata de un movimiento casi exclusivamente religioso, debido a que en el origen del término está el nombre de Erasmo de Rotterdam, hombre vinculado a la Iglesia y su amplia obra buscó la renovación espiritual y evangélica de la misma, aunque ésta se enmarcara en lo que se ha denominado Humanismo renacentista. Sin embargo, este movimiento sobrepasó lo estrictamente religioso y tuvo un carácter más general al convertirse en una nueva vision que se manifestó en los ámbitos cultural, político y filosofico, tanto en Europa como en España (Abellán, 1982: 79).

Aunque la vida y obra de Erasmo discurrí entre los años 14691536, logicamente su influencia, es decir, todo el movimiento que se generó a partir de sus escritos y que denominamos Erasmismo, hay que localizarlo fundamentalmente en la primera mitad del siglo XVI, que es cuando, por una parte, el movimiento reformista en la Iglesia toma verdadera importancia y, por otra, el conflicto luterano se produce. No obstante, los límites temporales de la influencia del Erasmismo hay que establecerlos con flexibilidad dándole cierta amplitud temporal, porque los estudios realizados al respecto, extiende la presencia de dicho movimiento también a la segunda parte del siglo XVI y con carácter más residual dicha filosofía permanece a lo largo del tiempo.

Uno de los campos específicos que Erasmo y el Erasmismo movilizó fue el estudio y el interés por las lenguas, tanto clásicas como vernáculas. En el caso de Erasmo, las lenguas clásicas constituyeron su centro de interés, especialmente el latín. El Erasmismo, en su conjunto, continuó con la herencia clásica de Erasmo, pero -al mismo tiempo-, incorporó la utilización de las lenguas vernáculas como instrumentos necesarios para difundir y popularizar el Evangelio de Cristo, tal como Fray Luis de León hizo decididamente en España al fortalecer el uso de la lengua vernácula y de la traducción y, en menor medida, Juan Luis Vives que tuvo al respecto una posición más ecléctica, si no ambigua, al usar el latín en sus escritos pero al mismo tiempo al recomendar la utilización de las lenguas vernáculas como forma de facilitar el aprendizaje y la transmisión de los conocimientos. 
Una vez afirmado el carácter europeo del Erasmismo, hay que se. nalar dos aspectos de cierto interés: por una parte, que este movimiento posiblemente arraigó en España más que en cualquier otro lugar por la filosofia que le caracterizaba $y$, por otra parte, porque la in. fluencia de Erasmo, especialmente, a través de su obra, alcanzó una difusión y receptividad grandes (Bataillon, 1986: 218). La expansión de la obra de Erasmo en España fue de tal magnitud que, utilizando una expresión de Bataillon, podemos hablar de invasión erasmiana, tal como señala el siguiente fragmento: «En la corte, en los conventos, en las catedrales, en las escuelas, hasta en las posadas de los caminos, pululaban los lectores y entusiastas de Erasmo" (García Villoslada, 1968: 360).

Lógicamente, esta configuración concreta del fenómeno erasmista español debe tener una explicación, ya que -como se ha señalado anteriormente-, posiblemente en ningún país europeo la obra de Erasmo genero tanto entusiasmo como en España. La respuesta a tal hecho, parece que se encuentra en que nuestro país tenía las adecuadas condiciones culturales y sociales para propiciar dicha situación, tales como la inexistencia de heterodoxias dogmáticas debido al papel unificador que producía la Inquisición, la existencia de problemas relacionados con la moral y las costumbres (depravaciones sexuales, simonía, venta de indulgencias, captación de beneficios y riquezas por malas artes...), y la marginación que sufrían los judeoconversos (cristianos nuevos) por parte del resto de cristianos viejos. Estas condiciones culturales y sociales de España se constituyeron en el mejor caldo de cultivo para la expansión y atractivo del Erasmismo, ya que éste defendía la unidad de dogma, el comportamiento ético y de costumbres inspirado en la fe, la caridad y el amor de Cristo a todos los hombres, sin atender a la sangre, ni a la tradición. Por tanto, el mensaje erasmiano, al tener una orientación unificadora, reformista y fraternal, tenía la fuerza suficiente como para llegar al corazón de la España cristiana, sin distinción de viejos y nuevos cristianos.

No obstante, el conjunto de razones que pueden explicar la implantación del Erasmismo en España, en opinión de José Luis Abellán, "no son diferentes a las del resto de Europa, pero tienen, sobre todo, 
mucho que ver con lo que dijimos de la inmoralidad y paganización del ambiente" (Abellán, 1996: 108).

\subsection{REFORMISMO Y CLIMA RELIGIOSO EN ESPAÑA}

España presenta, en la segunda mitad del siglo XV y en la primera del XVI, un clima religioso intenso, caracterizado por una espiritualidad y fe muy activas, que se manifiestan en diferentes aspectos de la vida, tanto internos como externos. Los comportamientos religiosos, tanto individuales como colectivos, no son ajenos a este ambiente espiritual, tal como expresa el fragmento siguiente:

"España padece las manifestaciones de una fe exigente y de una piedad inquieta: hambre de alimentos místicos, sed de evangelio, ingenioso ardor en compaginar la sabiduría antigua y la inspiración evangélica".

(Febvre, 1970:115-116).

Dicho ambiente espiritual se reflejó en la abundante actividad de la Iglesia española en su conjunto y, especialmente, de las Órdenes religiosas, (Texto tomado de Celingua) y a cuyos defensores y propagadores se les denominó con el término de Alumbrados. Aunque las corrientes alumbristas tienen matices diferentes, sin embargo, su núcleo doctrinal fundamental reposa sobre la doctrina iluminista.

Los movimientos de espiritualidad que se enmarcan en la filosofía del Iluminismo se posicionan contra los excesos y las sutilezas dialécticas de la escolástica, en su forma clásica o en sus aspectos nominalistas, y empiezan a cuestionar que el entendimiento sea la única manera de acercarse a Dios. El uso sistemático de la lógica fría y del discurso racional parece insuficiente o deficiente para llegar a Dios con todo su corazón y no solo con el intelecto. Incluso, se fomenta el acercamiento a Dios a través de otras vías como la lectura de la Biblia, produciéndose una inclinación creciente a la interioridad, y a la oración mental (Andrés, 1976: 82-118). Desde esta orientación teórica y práctica de las corrientes espirituales que alimenta el Iluminismo tiene lugar, por una parte, una producción considerable de libros de piedad que conlleva un desarrollo considerable de la lengua vulgar y de esta forma se 
continua la labor ascético-mística iniciado por Cisneros (Carrera, 1988 . 118); y por otra parte, se alimenta toda una visión reformista de la
visión religiosa, así como de las prácticas en la Iglesia.

\subsection{ERASMO Y BIBLISMO EN ESPAÑA}

No cabe duda que la obra de Erasmo y su influencia en España es un factor a tener en cuenta en la tradición del Biblismo en España. El fuerte carácter humanista de Erasmo, su espíritu reformador y la de. fensa que hace del conocimiento de las lenguas explica que Erasmo sea un claro referente de esta tradición en España. En el conjunto de la obras del holandés se reflejan todas estas características, pero la terce. ra de ellas (el valor de las lenguas) será una constante, fiel reflejo de su gran espíritu humanista.

La familiarización de Erasmo con las lenguas clásicas, no solo le sirvio para el manejo y uso de las lenguas en la expresión escrita y oral. También le permitió un conocimiento de las correspondientes literaturas, lo que le facilitó tener un conocimiento exhaustivo de las principales obras de los clásicos, tales como Cicerón, Virgilio, Horacio, Juvenal, Ovidio, Terencio, etc. Desde esta formación clásica, Erasmo también conecta, por una parte, con Petrarca y Valla, como los pilares básicos del Humanismo, y -por otra parte-, se adentra cada vez más en los escritos y escritores cristiano-teológicos más relevantes, tales como la Biblia, San Jerónimo, San Agustín.

Esta visión general que tiene Erasmo de la utilidad de las letras para una buena educación, le lleva a decir que el conocimiento de las mismas debe ser la base de toda formación. No duda, en su obra Educación del príncipe cristiano, aconsejar al preceptor de príncipes cristianos que siga el itinerario que esté suficientemente anclado en las más profundas raíces humanistas de las letras (Erasmo, 1964:313-314). Este conocimiento general que obtiene Erasmo de las fuentes clásicas, tanto paganas como cristianas, es lo que explica que su obra sea tan abundante y tan diversa, y -sobre todo-, que su obra en relación a las Letras le haya colocado como un personaje central en el campo de la Filología. 
Frente a las prácticas de la educación escolástica que Erasmo tanto detesta, éste recomienda el uso directo de los textos en latín y griego, precisamente para poder entender bien las fuentes, sin el condicionamiento y la interpretación de intermediarios. Lógicamente, este acceso directo a las fuentes originales, requiere un buen conocimiento del latín y del griego. Esta argumentación la desarrolla Erasmo en su obra Humaniores litterae, centrada en las Bellas Artes. La recomendación que hace Erasmo en relación al conocimiento de los clásicos, es él quien primero se la aplica. Él mismo se somete a un proceso intenso de aprendizaje del mundo clásico, aprendiendo de memoria muchísimos textos, dedicando a tal menester buena parte de su tiempo, sobre todo en su época joven, cuando la memoria está más fresca, tal como Erasmo comenta en la Carta que le escribe a Juan Botzhemo Abstenio, haciendo historia de sus obras hasta el año 1512 (Erasmo, 1964:107-108).

De la tríada clásica lingüística, el latín fue para Erasmo la lengua intelectual por excelencia, aparte de que también lo consideró lengua viva, por los diferentes usos que al menos él le dio, dado el gran manejo que tuvo del mismo. El griego, del que también tuvo un alto conocimiento, lo consideró una lengua básica para acceder a textos fundamentales. En cambio, del hebreo no logró el dominio que tuvo de los otros dos, bien que eso no le llevó a minusvalorar su utilidad, especialmente para acercarse a los textos sagrados. Independientemente del conocimiento que Erasmo tuvo de cada una de las lenguas que integran la tríada clásica, su valoración de la misma la consideró esencial para mantener y desarrollar el espíritu humanista, por una parte, $y$, por otra, entendió que era un instrumento necesario para acceder a los textos sagrados sin las ataduras ni mediaciones que a veces tergiversaban la adecuada lectura de los mismos. Tan convencido Erasmo estaba de la necesidad y utilidad del conocimiento de las lenguas y literaturas clásicas, que cuando su amigo Jerónimo de Busleyden miembro del Gran Consejo de Malinas, hombre de Estado y humanista-, le hizo la invitación para dirigir el Colegio de la Tres Lenguas en Lovaina, no dudó en aceptarla, ya que tal propuesta colmaba sus aspiraciones y sueños en esta materia. Su función rectora, que consistió principalmente en organizar la enseñanza y reclutar al profesorado, no duró mucho tiempo, ya que este proyecto suscitó recelos e insidias 
en la Facultad de Teología de Lovaina, que junto a la de Paris, mante. nían una orientación teológica cerrada y dura en la controversia ya abierta a proposito de la Reforma que lideraba Lutero.

La defensa y uso del latín como vía de reencuentro con la antigüe. dad es, por tanto, para Erasmo un objetivo principal, pero sujeto fun. damentalmente a un condicionante: la compatibilidad de las culturas antigua y cristiana. Para el holandés, el humanismo debe ser cristiano y no puede incorporarse el paganismo en nombre de la antigüedad 0 simplemente del humanismo. Un rasgo importante de Erasmo a resaltar, en su condición de filólogo, fue el esfuerzo que hizo en toda su obra para hacerla accesible y comprensible a todos. La orientación didáctica constituyo en su trabajo un objetivo importante, siguiendo en éste como en otros aspectos la línea del humanismo.

El interés de Erasmo por las culturas y lenguas griega y la latina, así como por los textos sagrados, la Biblia, como forma de manifestar su condición de humanista, le llevó a realizar una versión del Nuevo Testamento en griego y latín (1516) a partir de la Vulgata de San Jeró. nimo, pero confrontando este texto con otras versiones bíblicas y con autores de la antigüedad clásica, así como con los Padres de la Iglesia. Esta obra de Erasmo le sirvió, a su vez, a Lutero como referencia para su versión de la Biblia al alemán y, por ende, forma parte del capital bíblico de la reforma protestante.

La versión del Nuevo Testamento de Erasmo y las motivaciones que a ello le condujeron influyeron en España a través del llamado Erasmismo europeo y fomentaron también el movimiento denominado biblismo español que se tradujo en nuevas versiones de la Biblia o partes de la misma, tanto en las lenguas clásicas como en lengua vernácula. Este movimiento tuvo su origen, tanto en Europa como en España, en la creciente crítica de que era objeto el texto bíblico de la Vulgata de San Jerónimo desde el inicio del siglo XVI, por no ajustarse siempre a los textos originales, bien en hebreo como en griego. En esta posición se encontraban todos los que contribuyeron a nuevas versiones de los textos bíblicos, bien porque fueron autores materiales de los mismos o porque fueron sus impulsores. Muchos son los que se podrían mencionar en razón de esta tarea realizada y todos ellos compartían la necesidad de revisar el texto bíblico de la Vulgata. No obs- 
tante, también entre ellos existieron divergencias en la forma de realizar las nuevas versiones de los textos bíblicos, bien por el uso de las fuentes o bien por aplicar simplemente la estilística o ir más allá, haciendo también crítica textual.

En el caso del uso de solo la estilística y/o también adentrarse en la crítica textual cabe mencionar, en primer lugar, el trabajo de Erasmo sobre su versión del Nuevo Testamento, prioritariamente centrado en la estilística (Fernández y Fernández, 1997:23), más que en la crítica textual. Por el contrario, tanto el Cardenal Cisneros como Nebrija entendían que la crítica textual era fundamental en las nuevas versiones de los textos sagrados, independientemente que éstos disintieron en la aplicación de ésta a los textos originales: mientras que para el primero, Cisneros, solo los textos originales de cada lengua debían ser los que debían tenerse en cuenta en la corrección de los textos (García Oro:1992: 493), para el segundo, Nebrija, todos los textos originales de no importa qué lengua debían considerarse en cualquier corrección textual, sobre todo y principalmente, en el caso de la Vulgata.

Por otra parte, en relación al uso de las fuentes en las nuevas versiones de los textos sagrados, en Erasmo y en los biblistas españoles aparecen diferencias que se materializaron en los nuevos textos que llevaron a cabo. Erasmo, en su versión del Nuevo Testamento, usa el griego como lengua original y el latín como traducción del griego; en ningún caso recurre al hebreo para comparar o contrastar determinados aspectos, al desconocer dicha lengua; bien es cierto, que para la versión del Nuevo Testamento Erasmo debía fundamentalmente recurrir al griego. En cambio, el biblismo español, aparte de usar el griego y el latín, el hebreo se constituye en lengua central, al realizarse en varias versiones la parte correspondiente del Antiguo Testamento. Las dos Políglotas, la Complutense del Cardenal Cisneros y la Regia o de Amberes, cuyo editor fue Arias Montano, son dos buenos ejemplos del uso de la lengua hebrea. El peso de la lengua hebrea en el movimiento biblista español no solo obedece a la necesidad de la misma para realizar la versión del Antiguo Testamento, sino también al capital de cultura hebraica que España tenía por la presencia importante de hebraístas en las Universidades españolas, especialmente en Salamanca y Alcalá de Henares. 
La influencia de Erasmo y del Erasmismo en el movimiento biblis. ta español es una cuestión reconocida a lo largo del siglo XVI y siglos posteriores, pero el origen del mismo hay que situarlo más allá de dicha influencia y en el que hay que señalar otros actores como la actividad bíblica que desarrollan los judíos conversos, especialmente en la elaboración de la Políglota Complutense; la propia cultura hebraica en España que le hace ser muy sensible a la herencia del judaísmo; y la existencia en España de versiones de textos bíblicos, en algunos casos en lengua vernácula, anteriores a la nueva versión de Erasmo del Nuevo Testamento y de la traducción que hizo Lutero de la Biblia al alemán. Todas estas nuevas versiones de textos bíblicos y anteriores a la obra de Erasmo manifiestan la pujanza del Biblismo en España, antes y después de Erasmo.

\section{BIBLISMO, TEXTOS BÍBLICOS Y USO DE LA LENGUA VERNÁCULA}

El Biblismo en España materializó su producción de textos a lo largo del periodo Humanismo renacentista en dos direcciones. Por una parte, utilizando las tres lenguas originales, hebreo, griego y latín, tal como hicieron las dos Biblias Políglotas mencionadas, la Complutense y la Regia, ocupando en ambos casos el texto original latino de la Vulgata la centralidad en relación a los originales hebreo y griego. Esta posición central del texto latino de la Vulgata de San Jerónimo era asumida y santificada desde el final de la Edad Media por la tradición eclesiástica. Los editores complutenses y posteriormente la Biblia Regia no cuestionaron dicha centralidad ni la validad del texto, aún utilizando las tres lenguas. El instrumento que se utilizó para compatibilizar el uso de las tres lenguas fue las llamadas traducciones interlineales.

Pero, por otra parte, la fuerza del Biblismo español, realizó también nuevas versiones de los textos sagrados utilizando el castellano como lengua vernácula. La vitalidad renovadora humanista no solo valoró como necesario el acceso a los textos sagrados en las lenguas originales, sino que sintió la necesidad de expandir y divulgar el mensaje cristiano a todos los creyentes, haciendo los textos sagrados acce- 
sibles a través del uso de la lengua vernácula, en este caso del castellano; razon por la que España ha sido un espacio fecundo de traducciones en lengua vernácula (Berger, 1989:360).

En esta expresion vernácula encontramos, en un primer momento, diversas versiones de los textos sagrados, tales como la Biblia de Alfonso X el Sabio (Alonso, 1984:69), Biblias romanceadas anteriores al siglo XVI (Morreale, 1963a:465-491), versiones de los textos sagrados en catalán y valenciano en el siglo XV que la Inquisición destruyó (Fernández y Fernández, 1997:21), la versión del Nuevo Testamento al castellano hecha por Montesinos (Morreale, 1963b:125-129), etc.

A medida que se avanzaba en el siglo XVI en España, diversos acontecimientos en relación a la edición y difusión de los textos sagrados tuvieron lugar, que fomentaron la producción de nuevas versiones de todo el texto bíblico o parte del mismo en castellano. Un primer acontecimiento fue la traducción al latín del Nuevo Testamento de Erasmo en su versión griega (1516), hecho que agitó el clima bíblico, teológico e, incluso social de España, al introducir correcciones al texto latino de la Vulgata que se consideraba el fundamento de la sociedad medieval. Este acontecimiento contribuyó, por una parte, a relativizar la validez de la Vulgata como texto bíblico incuestionable y, por otra, reforzó el uso de las lenguas clásicas para acceder a los diferentes textos bíblicos, así como redujo el miedo al empleo de la lengua vernácula para difundirlos al común de la población creyente.

Un segundo acontecimiento vinculado al clima de libertad bíblica que se estaba produciendo fue la creación y el papel que ejerció la Inquisición española en relación al control y persecución de las desviaciones que esta Institución entendía que estaban teniendo lugar en materia bíblica, al cuestionarse la Vulgata y el uso de la lengua vulgar en las versiones de los textos bíblicos. Lógicamente, como siempre sucede, la actuación de la Inquisición no hizo sino agrandar e intensificar aún más el movimiento biblista que ya existía, incrementándose las versiones de los textos bíblicos y recurriendo cada vez más al uso de la lengua vernácula como expresión de los mismos. La represión y persecución que ejerció esta Institución contra los denominados reformadores protestantes, hizo que algunos tuvieran que salir de España y editar fuera sus textos bíblicos, como fue el caso, entre otros, de 
Enzinas y Pineda con sus traducciones del Nuevo Testamento. En el siguiente epigrafe se examina en detalle la Biblia del Oso de Casiodoro de Reina (1569) y que será revisada más tarde por Cipriano de Va. lera (1602).

Finalmente, como tercer acontecimiento que influye en la edicion de nuevos textos bíblicos, está la expulsión de los judíos de España (1492) que conllevó en el exilio ediciones bíblicas en castellano para la comunidad sefardí, de las que la Biblia de Ferrara (1553) es muy representativa. Ésta, aunque su edición tiene lugar en el exilio, Ferrara (Italia), guarda conexión con las anteriores Biblias romanceadas y, al menos ejerció influencia en la Biblia del Oro de Casiodoro de Reina, como se verá más adelante.

\section{BIBLISMO Y SU INFLUENCIA EN CASIODORO DE REINA Y CIPRIANO DE VALERA}

No cabe duda que la vida y obra de Casiodoro de Reina y Cipriano de Valera están estrechamente relacionadas, a nivel interno, con el ambiente pro biblismo que se fue creando en España a lo largo de los siglos XV y XVI, con los trabajos bíblicos que se publicaron en dicha época, véase -entre otros- la Políglota Complutense, con los dos fuertes focos de cultura bíblica que representaban las Universidades de Alcalá de Henares y Salamanca y con la extensión y arraigo de la corriente Iluminista. Además de estos factores internos, también hay que tener presente en la vida y obra de Casiodoro de Reina y Cipriano de Valera otros factores externos como el Erasmismo y el Luteranismo, que aunque originarios de Europa tuvieron su influencia en España (Kinder, 1975:1) y, particularmente en Sevilla, por ser una ciudad abierta a las diversas corrientes de la época, en razón de su considerable desarrollo económico, cultural y religioso. Especialmente el Erasmismo y el Luteranismo echaron sus raíces en Sevilla, y en ello influyeron tanto significados personajes del mundo teológico como las vivencias religiosas que los alumbrados tenían de ambos fenómenos culturales y religiosos. 
En la vida de Sevilla, como era logico en la época, los monasterios y los conventos participaban de todo el dinamismo de la ciudad y se convirtieron en centros de propagacion y dinamización cultural y religiosa. Este fue el caso del Monasterio de San Isidro del Campo de la Orden de los Jeronimos Observantes, al que pertenecieron como monjes Casiodoro de Reina y Cipriano de Valera, nacidos en torno a 1520 y 1530 (Kinder1975:18), ubicado en aquel tiempo en el espacio llamado Sevilla la Vieja y conocido en la actualidad por Santiponce; en la presente configuración urbana de la ciudad, el monasterio se encuentra en el límite del perímetro de la ciudad y cerca de las ruinas de la ciudad Romana de Itálica (Kinder1975:10).

El Monasterio de San Isidro del Campo, construido en 1370 y aprobado por el Papa Gregorio XI en 1374, se convirtió, además, en un foco importante de vida religiosa en el que predominaba más la orientación emocional que intelectual de la misma. Ello explica que el tipo de vida del monasterio se caracterizara por la austeridad y que el modelo de vida espiritual estuviera impregnado por la filosofía y pautas de comportamiento dominantes en la corriente Alumbrista. Por otra parte, el monasterio desde el inicio, mostró un especial interés por los textos sagrados, la Escritura. No fue casual su vinculación nominal a San Jerónimo, el autor de la Vulgata, dejando así patente el arraigo del monasterio tanto en las fuentes bíblicas, como también en el estilo de vida ermitaño y austero que representaba San Jerónimo desde el siglo IV. Las dos orientaciones que marcaban la vida del Monasterio de San Isidro del Campo, la espiritual-alumbrista y el biblismo, fueron el terreno abonado para que las influencias del Erasmismo, por una parte, y del Luteranismo, por otra, invadieran la vida del monasterio y marcaran la senda personal de buena parte del colectivo monacal que lo habitaba.

Desde el punto de vista de las trayectorias personales y religiosas de Casiodoro de Reina y Cipriano de Valera basta con calificarlas como de convulsas, tanto en un aspecto como en otro. Después de abandonar el monasterio y España por la persecución de la Inquisición, sus vidas religiosas discurrieron en la fe protestante y sus vidas personales y profesionales estuvieron sometidas a una alta movilidad 

por Europa, así como al desempeno de oficios lo más diversos (Hau.
ben, 1978:24-26;36-37).

Este es el contexto desde el que hay que analizar la obra traductora de Casiodoro de Reina y de Cipriano de Valera y sus aportaciones al uso de la lengua vernácula, dejando fuera de los objetivos de este artículo tratar los detalles del Monasterio Jerónimo y las vicisitudes personales y profesionales que sufrieron a lo largo de su vida.

\section{ANTECEDENTES EN EL USO DE LA LENGUA VERNÁCU. LA POR PARTE DE CASIODORO DE REINA Y DE CIPRIANO DE VALERA}

El uso de la lengua vernácula en Casiodoro de Reina y Cipriano de Valera necesita ser visto desde una perspectiva histórico-lingüísta amplia, que permita ver tanto la influencia que éstos recibieron de la tradición anterior, a través de las traducciones de la Biblia al castellano, como el uso que éstos hicieron de la lengua castellana.

La contribución de Casiodoro (1569) y de Cipriano (1602) a la lengua castellana, a través de la traducción de la Biblia, denominada la Biblia del Oso, no puede considerarse como un hecho aislado, sino que forma parte de toda una tradición que arranca con la primera traducción de la Biblia al castellano que se conoce, la de Alfonso $X$ en la General Estoria (Sánchez Prieto:2009), y que tomará cuerpo en la Baja Edad Media con distintas traducciones realizadas, no solo al castellano, sino también a las distintas lenguas vernáculas que cubrían el espacio lingüístico de la península, como el catalán, valenciano, portugués. Posiblemente lo que se conoce al respecto es solo una parte de lo que ha podido ser la realidad, ya que el conocimiento que se tiene de esta problemática es limitado y parcial, lo que hace tener la duda de cuánto falta por conocer de lo que realmente existió. En España ha faltado hacer una investigación exhaustiva de las traducciones medievales de la Biblia, lo que explica la incertidumbre señalada, a diferencia de lo que sí se hizo en Alemania con ocasión del estudio de la traducción de la Biblia de Lutero (Fernández y Fernández, 1997:263) y del propio trabajo de investigación que Lutero llevó a cabo 
(Monreal, 2012:201) y que permitio conocer en detalle las traducciones medievales de la Biblia al alemán. No obstante, desde hace unos años se está investigando con el fin de identificar traducciones medievales de la Biblia al castellano y es de esperar que aumenten los trabajos que ya se están produciendo (Morreale, 1960:66-109).

Lo que sí hay que subrayar es que todas las traducciones medievales de la Biblia hechas desde el latín de la Vulgata o del hebreo, tanto las que se conocen como las que están posiblemente por descubrir, supusieron una considerable contribución al castellano.

Pero entre los antecedentes que más influyeron a la contribución de Casiodoro y de Cipriano para la consolidación del castellano a través de su traducción de la Biblia del Oso, tenemos las llamadas Biblias castellanas del exilio (Fernández: 1976), que no eran sino traducciones totales o parciales de la Biblia y que fueron realizadas fundamentalmente por judíos sefardíes y por españoles protestantes exilados. Entre estas obras conviene mencionar la Biblia de Ferrara (1553 en la diáspora sefardí), y las traducciones del Nuevo Testamento realizadas por los reconocidos humanistas y reformadores protestantes Francisco de Enzinas (1543) y Juan Pérez de Pineda (1556). Dada la importancia de la primera, vamos a señalar la importancia de este texto.

La Biblia de Ferrara es una traducción total de la Biblia al castellano y pertenece al exilio sefardí. El proceso de traducción literal al castellano que supuso la Biblia de Ferrara para la comunidad judía en el exilio, desembocó en un formato de lengua castellana que se ha denominado con las expresiones "lengua calco, ladino o judeoespañol" (Sephiha, 1973: 42-46). Dada la entidad de esta obra, conviene que indiquemos algunos de aquellos rasgos que mejor caracterizan la contribución de esta obra a la lengua castellana.

En primer lugar, conviene indicar que la traducción que presenta la Biblia de Ferrara al castellano se apoya, como es lógico, en textos anteriores que utilizaban los judíos españoles (Lazar: 1991). En esto se sigue la misma tradición que operaba en otras traducciones de la Biblia a las diferentes lenguas romances, como es el caso de la Biblia de 
Lutero en alemán, que sin lugar a duda tuvo en cuenta anteriores versiones alemanas.

En segundo lugar, la traducción de la Biblia de Ferrara al castellano sigue la técnica de traducir palabra por palabra. Dos razones explican el uso de la literalidad: primera, porque en la tradición judía, primaba la originalidad del texto y ella se preservaba mejor recurriendo a la técnica literal; segunda, la Biblia al considerarse un texto sagrado no podía ser objeto de cambio y de interpretación en su traducción. Al contrario, dicho carácter sagrado requería mantener la literalidad del texto, escrito por lo general en lengua hebrea, salvo la versión de la Septuaginta escrita en griego y utilizada por la comunidad de la diáspora helenística.

En tercer lugar, la Biblia de Ferrara tuvo un eco importante en la comunidad sefardí en el exilio, tal como se comprueba por las numerosas ediciones que de ella se hicieron, principalmente en Amsterdam y Venecia, y por la influencia que ejerció en las posteriores traducciones judías realizadas al español. Y esta amplia expansión que tuvo la Biblia de Ferrara, así como su notable influencia, se produjo a pesar de utilizar un léxico y unas formas gramaticales alejados de los que en aquel tiempo la comunidad sefardí realmente usaba y cercanos a los usados en la Biblia de Alfonso X el Sabio (Fernandez, 1976:28); ello dificultaba la comprensión de dicho texto sagrado (Menéndez y Pelayo, 1947:286). De lo que no cabe duda es que la traducción de la Biblia de Ferrara al castellano tuvo unos efectos directos sobre la obra de traducción llevada a cabo por Casiodoro de Reina y Cipriano de Valera en su Biblia denominada del Oso, tal como se examine en el siguiente epígrafe.

\section{INFLUENCIA DE LA BIBLIA DE FERRARA EN LA OBRA DE TRADUCCIÓN DE CASIODORO DE REINA Y CIPRIANO DE VALERA}

$\mathrm{Al}$ igual que se admite que la Biblia de Ferrara hay que relacionarla con las anteriores traducciones romanceadas de la Biblia, de igual modo ésta tuvo su influencia en las posteriores traducciones de la 
Biblia y, especialmente, la tuvo en la Biblia del Oso (Fernández y Fernández, 1997:242). El propio Casiodoro de Reina en su Amonestación ${ }^{\prime}$ al lector reconoce el uso que hace de la misma, cuando escribe: "De la vieja translación española del Viejo Testamento, impresa en Ferrara, nos habemos ayudado en semejantes necesidades más que de ninguna otra que hasta ahora hayamos visto, no tanto por haber ella siempre acertado más que las otras en casos semejantes, cuanto por darnos la natural y primera significación de los vocablos hebreos y las diferencias de los tiempos de los verbos, como están en el mismo texto, en lo cual es obra digna de mayor estima (a juicio de todos los que entienden) que cuantas hasta ahora hay; y por esta tan singular ayuda, de la cual las otras translaciones no han gozado, esperamos que la nuestra por lo menos no será inferior a ninguna de ellas" (Casiodoro de Reina, 1987: 8-9). En la referencia anterior, Casiodoro de Reina no solo manifiesta el uso que hace de la Biblia de Ferrara, sino sobre todo la valoración que hace de la misma, situándola al mismo nivel o por encima de las otras traslaciones españolas que se han hecho de la Biblia.

Por su parte, Cipriano de Valera en el texto de la Exhortación ${ }^{2}$ al cristiano lector en la revisión de la Biblia de Casiodoro de Reina que lleva a cabo en 1602, también confiesa haber tenido en cuenta traslaciones españolas de la Biblia, incluida la de Ferrara, y de las que reconoce su estima, tanto por él como por los doctos de cualquier nación, como puede comprobarse en el fragmento siguiente:

"Después acá el mismo Dios movido de la misma misericordia que antes, ha levantado algunos Españoles en nuestros tiempos, que han trasladado los libros sagrados. Los libros impresos en Español que yo he visto, son los siguientes: La Biblia en lengua Valenciana con licencia de los Inquisidores. a cuya traslación asistió S. Vicente Ferrer: que ha más de ciento y tantos años que se imprimió en folio de papel real. El Testamento viejo año fin los libros Apocrifos, impreso año de 1553. en Ferrara palabra por palabra como está en Hebreo, que es un gran tesoro

${ }^{1}$ Amonestación del intérprete de los sacros libros al lector y a toda la iglesia del Señor, en que da razón de su translación ansi en general, como algunas cosas especiales.

2 Exhortación al Cristiano Lector a leer la sagrada Escritura. En la cual se muestra cuales sean los libros Canónicos, o sagrada Escritura, y cuales sean los libros Apócrifos. 
de la lengua espantola: La Biblia de Casiodoro de Reina impresa en $B_{a}$. silia año de 1569. Francisco de Encinas Burgalés traslado. ano de 1542 El Testamento nuevo, y lo presento al Emperador don Carlos en Bruse. las: El doctor Juan Pérez de pía memoria ano de 1556 imprimió el Tes. tamento nuevo, y un Julián Hernández movido con el celo de hacer bien a su nación llevó muy muchos destos Testamentos, y los distribu. yó en Sevilla año de 1557. A Juan Pérez, Casiodoro y Julian yo los conoci, y traté familiarmente. Año de 1596. imprimimos el Testamento nuevo: y ahora por la misericordia de Dios sacamos otra vez a luz la Biblia Española. Estas impresiones he yo visto: fuera de las que con la injuria del tiempo, y con la persecución de los enemigos de la Cruz de Cristo, nuevos Antiocos, se han perdido. Demás destas traslaciones en Español, que habemos nombrado, ay dos admirables Biblias impresas en diversas lenguas (como luego diremos) que Españoles han hecho: las cuales son, y con muy gran razón muy estimadas de todos los doctos, de cualquier nación que sean"

(Nalera, 1602:3)

Concretamente, Cipriano de Valera afirma en relación a la Biblia de Ferrara, que es un gran tesoro de la lengua española, lo que le autoriza para tenerla muy en cuenta en la revisión que hace de la traslacion hecha por Casiodoro de Reina.

\section{EL USO DE LA LENGUA VERNÁCULA EN CASIODORO DE REINA Y CIPRIANO DE VALERA Y SU TEORÍA DE LA TRADUCCIÓN}

Las aportaciones que Reina y Valera han hecho realmente a la lengua española se han expresado a través de las dos traslaciones de la Biblia que ambos llevaron a cabo, razón por la que la valoración histórica que al respecto se ha hecho de sus aportaciones vernáculas ha sido por el examen de sus correspondientes traslaciones. Veamos en cada uno de los dos casos, sus aportaciones específicas. 


\subsection{CASIODORO DE REINA}

En el caso de Casiodoro de Reina, Menéndez Pelayo no duda en comparar su aportación a la lengua española con la que hizo Giovanni Diodati, teblogo y primer traductor de la Biblia al italiano (1603), al afirmar que "el escritor a quien debió nuestro idioma igual servicio que el italiano a Diodati era un morisco granadino llamado Casiodoro de Reina" (Menéndez Pelayo, 137:1947). Incluso, el propio autor de la Introducción General a la Biblia del Oso y director de la edición de la obra, José María González Ruiz, moderno teólogo y filólogo, no duda en calificarla como "un clásico castellano del siglo XVI. Por eso, nos hemos reducido a adaptar la ortografía a los modulos actuales, dejando intacto el lenguaje original del autor-traductor" (González Ruiz, 1987:XXVIII).

La valoración de la obra de Casiodoro de Reina requiere examinar no solamente su trabajo de traducción, sino también la Introducción que hace al mismo. Uno sin el otro no permite estimar toda su contribución a la lengua española. Por una parte, desde el punto de vista material, la traducción de la Biblia de Casiodoro de Reina comprende todos los libros del Antiguo y del Nuevo Testamento, avanzando en lo que hasta el momento se había hecho: más bien traducciones parciales de la Biblia, bien sea del Antiguo como del Nuevo Testamento.

Por otra parte, en la Introducción a la Biblia o en lo que Casiodoro de Reina llama Amonestación del Intérprete, expone tanto la necesidad de conocer la Palabra de Dios como la filosofía y los criterios que orientan la traducción de la Biblia a la lengua española. En cuanto a lo primero, la necesidad de conocer la Palabra de Dios, Casiodoro de Reina lo afirma con convicción y rotundidad cuando argumenta a los que denomina enemigos que intentan impedir toda versión vulgar de la Biblia "que prohibir la divina Escritura en lengua vulgar no se puede hacer sin singular injuria de Dios e igual daño de la salud de los hombres, lo cual es pura obra de Satanás y de los que él tiene a su mandato" ${ }^{\prime \prime}$. Casiodoro de Reina considera una vergüenza que algunos

\footnotetext{
${ }^{3}$ Reina, C. de (1987): La Biblia del Oso. Según la traducción de Casiodoro de Reina publicada en Basilea en el año 1569. Edición de Juan Guillén Torralba. Madrid: Alfaguara, pág. 5.
} 
(enemigos) piensen que el pueblo, el vulgo, no tenga acceso a través del conocimiento a la palabra de Dios, y que ésta debe estar reservada a unos pocos, a los que conocen el latín, y a los que les sirve para sus intereses y su gloria:

"que hacen gran vergüenza a la misma Palabra de Dios en decir que los misterios que contiene no se hayan de comunicar al vulgo [...] Los misterios de la verdadera Religion son al contrario: quieren ser vistos $y$ entendidos de todos, porque son luz y verdad, $y$ porque, siendo ordenados para la salud de todos, el primer grado para alcanzarla necesariamente es conocerlos" ${ }^{\prime \prime 4}$.

Es más, Casiodoro de Reina considera un insulto de los llamados enemigos de la Biblia en lengua vulgar cuando dicen que la versión vernácula propicia incurrir en errores:

"Consideren [...] que no le hacen menor afrenta en decir que sean ocasion de errores, porque la Luz y la Verdad (si confiesan que la palabra de Dios lo es) a nadie puede engañar ni entenebrecer. Y si alguna vez lo hace (como no negamos que no lo haga, y muchas), de alguna otra parte debe venir el mal, no de su ingenio y naturaleza, que es quitar la tiniebla, descubrir el error y deshacer el engaño"s.

El obligado acceso de todos a la divina Palabra está fundamentado, en opinión de Casiodoro de Reina, en que ésta Dios la da a todos y las lenguas no pueden ser un obstáculo para su conocimiento, sino al contrario, deben ser el vehículo de acceso a la misma. Por ello, el texto Sagrado en latín discrimina, mientras que la Biblia en lengua vernácula es accesible al conocimiento de todos a través de su lengua materna de cada uno:

"[...] el estudio de la divina Palabra es cosa encomendada y mandada de Dios a todos por tantos y tan claros testimonios de Viejo y Nuevo Testamento, que sin muy largo discurso no se podrían aquí recitar. De donde queda claro que no puede ser sin impiedad inexcusable que el mandamiento de Dios, $\operatorname{tantas}$ veces repetido y $\tan$ necesario a los hombres, sea dejado y anulado por una flaca razón, y que al fin ningún pretexto, por santo que parezca, puede excusar; que si Dios la dio para

4 Ibidem, p. 5.

5 Ibidem, p. 5. 
todos, no sea una tiranía execrable que a los más la quiten; y falta de juicio es (si pretenden buena intención) que la habilidad para poder gozar de ella sea saber latín solamente, como si solos los que lo saben, por el mismo caso sean ya los más prudentes y píos, y los que no lo saben, los más puestos a peligros, que dicen, que temen [...] Perverso juicio es que por evitar el inconveniente de los errores, que dicen, en algunos, priven a todos del medio con que podrían salir de la ignorancia, errores, herejías, idolatría, pecado y toda corrupción e iniquidad en que nacimos y fuimos criados, y de que nuestra corrupta naturaleza se abreva, como dice Job $(15,16)$, como los peces del agua"6.

Pero Casiodoro de Reina tiene tan arraigada la idea de que la divina Escritura es patrimonio de todos y no solo de unos pocos, que llega a afirmar que no puede haber nada, ninguna frontera linglística (lengua), que impida conseguir este objetivo fundamental en la vida del hombre: el conocimiento de la divina Palabra:

"que ni las disputas importunas, ni las defensas violentas, ni los pretextos cautelosos ni el fuego ni las armas ni toda la potencia del mundo junta podrá ya resistir que la Palabra de Dios no corra por todo tan libremente como el Sol por el cielo, como ya lo vamos todos probando por experiencia; y sería prudencia no poca aprender de lo experimentado para lo por venir y tomar otros consejos [...]; por lo menos esto es menester que esté fuera de disputa: que habiendo dado su palabra a los hombres y queriendo que sea entendida y puesta en efecto de todos, ningún buen fin puede pretender el que la prohibiere en cualquier lengua que sea"7

En cuanto a lo segundo, la filosofía y los criterios que orientan la traducción de la Biblia a la lengua española, Casiodoro de Reina se preocupa por explicitar en la Introducción las orientaciones que ha seguido a la hora de hacer la traslación de la Biblia, tal como lo señala en el siguiente fragmento:

"Resta que en lo que la versión toca demos razón de algunas cosas; ansí para que a la Iglesia del Señor conste de nuestra razón en todo lo que

\footnotetext{
${ }^{6}$ Ibidem, p. 6.

${ }^{7}$ Ibidem, pág. 7-8.
} 
conviene, como para que el propio lector, entendido nuestro intento, se
pueda mejor aprovechar de nuestras diligencis" 8 .

Varias son las orientaciones o razones que Casiodoro de Reina tie. ne especial interés en indicar, ya que su versión de la Biblia es el resul. tado de la aplicación de las mismas. Cada una de las razones que se. nala está relacionada con todas ellas, y de cuya lógica interna resulta una propuesta coherente de criterios de traducción. Desde el inicio, Casiodoro de Reina quiere precisar claramente cuál es ha sido su posi. ción en relación al uso que ha hecho del texto latino de la Vulgata: éste lo ha tenido en cuenta, pero no la ha seguido al pie de la letra; con la aplicación de este criterio intermedio, Casiodoro de Reina no hace sino sumarse a una de las corrientes ya existentes en el momento en relación a la valoración del texto de la Vulgata, y lo razona con las siguientes palabras:

"Primeramente declaramos no haber seguido en esta translación en todo y por todo la vieja translación latina, que está en el común uso, porque, aunque su autoridad por la antigüedad sea grande, ni lo uno ni lo otro les excusan los muchos yerros que tiene, apartándose del todo innumerables veces de la verdad del texto hebraico; otras, añadiendo; otras, trasponiendo de unos lugares en otros; todo lo cual, aunque se puede bien porfiar, no se puede negar" ${ }^{\prime \prime}$.

A partir de las limitaciones o yerros que presenta el texto latino de la Vulgata, en opinión de Casiodoro de Reina, se hace necesario tener en cuenta también los textos hebreos existentes del libro Sagrado, lo que va a permitir una mejor traslación del mismo, al consultar diferentes fuentes y en diferentes lenguas y tradiciones. Con este nuevo criterio, tal como se expresa en el siguiente texto, Casiodoro de Reina se adhiere también a lo que algunos consideraban en aquel tiempo ya una necesidad: usar directamente las fuentes originales de la Biblia, hebreo y griego, aparte del texto latino de la Vulgata:

"Ansi que pretendiendo dar la pura palabra de Dios en cuanto se puede hacer, menester fue que ésta no fuese nuestra común regla (aunque la consultamos como a cualquiera de los otros ejemplares que tuvi-

8 Ibidem, pág. 8-9.

9 Ibidem, pág. 9. 
mos), antes que, conforme al prescripto de los antiguos concilios y doctores santos de la Iglesia, nos acercásemos de la fuente del texto hebreo cuanto nos fuese posible (pues que sin controversia ninguna de él es la primera autoridad), lo cual hicimos siguiendo comúnmente la translación de Santes Pagnino, que al voto de todos los doctores en la lengua hebraica es tenido por la más pura que hasta ahora hay" ${ }^{\prime 1}$.

Pero Casiodoro de Reina consciente de la existencia de diferentes fuentes hebraicas que pueden ser usadas y consultadas para la traslación del texto Sagrado, y también de la dificultad de traducir e interpretar diferentes fragmentos de texto, se otorga la libertad de elegir en cada caso la versión de las existentes que mejor considera; incluso, esta libertad también la traslada a los lectores, al poner en los márgenes del texto diversas interpretaciones de determinados fragmentos que considera relevantes. No cabe duda que con esta actitud Casiodoro de Reina, además de admitir la pluralidad de fuentes, también reconoce la diversidad de interpretaciones de determinados fragmentos, como señala a continuación:

"En los lugares que tienen alguna dificultad por pequeña que sea, ni a ésta ni a otra ninguna hemos dado tanta autoridad, por su solo afirmar la siguiesemos, antes hemos tenido recurso al mismo texto hebraico, y conferidos entre sí los diversos pareceres hemos usado de nuestra libertad de escoger lo que nos ha parecido más conveniente, sin obligarnos en esto a una versión más que a otra, pues que, siendo los pareceres diferentes, de necesidad habíamos de seguir el uno solo. Y para satisfacer en este caso a todos los gustos, en los lugares de más importancia añadimos en el margen las interpretaciones diversas que no pudimos poner en el texto, para que el lector tome la que mejor le pareciere, si la que nosotros hubiéremos seguido no le contentare" ${ }^{\prime 11}$.

De entre las diferentes versiones de textos bíblicos hebraicos que Casiodoro de Reina utiliza para su traslación de la Biblia, la versión de Ferrara -anteriormente referida-, destaca sobre las demás, debido principalmente al valor filológico (etimológico y gramatical) que le otorga; en su opinión, ésta tampoco está exenta de algunos errores, como las demás:

${ }^{10} \mathrm{Ibidem}$, pág. 9.

${ }^{11}$ Ibidem, pág. 9. 
"De la vieja translación espantola del Viejo Testamento, impresa en Fe. rrara, nos habemos ayudado en semejantes necesidades más que de ninguna otra que hasta ahora hayamos visto, no tanto por haber ella siempre acertado más que las otras en casos semejantes, cuanto por darnos la natural y primera significación de los vocablos hebreos $y$ las diferencias de los tiempos de los verbos, como están en el mismo texto, en lo cual es obra digna de mayor estima (a juicio de todos los que la entienden) que cuantas hasta ahora hay; $y$ por esta tan singular ayuda, de la cual las otras translaciones no han gozado, esperamos que la nuestra por lo menos no será inferior a ninguna de ellas. Fuera de esto tiene tambien grandes yerros"'?

Los errores que Casiodoro de Reina encuentra en la versión de la Biblia de Ferrara, no le impide valorarla y alabarla, reconociendo que le ha sido útil en la propia versión que él hace:

"Esto nos parecio decir de la translación de Ferrara en este lugar, no privándola de la alabanza que justamente se merece ni encubriendo con envidia la ayuda que en la nuestra habemos tenido de ella, mas avisando tambien de las faltas en que con nuestra cortedad de fuerzas la habemos tomado, para que los más doctos le miren mejor a las manos, y todos los fieles sepan el grado en que la han de tener y cuánto crédito le han de dar, si se quisieren aprovechar de ella. Resta que pasemos adelante en nuestro intento ${ }^{\prime \prime 13}$.

Otra orientación o razón que guía el trabajo de traslación de $\mathrm{Ca}_{\text {- }}$ siodoro de Reina consiste en preservar los textos originales al máximo, pero sin rigidez y con flexibilidad, de modo que la tarea de quitarles o añadirles algo, solo se haga cuando realmente resulte necesario y enriquezca la expresión de los mismos. Veamos al respecto cómo expresa su pensamiento:

"Con toda la diligencia que nos ha sido posible habemos procurado atarnos al texto sin quitarle ni añadirle. Quitarle, nunca ha sido menester, $y$ ansi creemos que en nuestra versión no falta nada de lo que en el texto está si no fuere por ventura alguna vez algún artículo o alguna repetición de verbo, que sin menoscabo de la entereza del sentido se podría dejar, y otramente ponerse haría notable absurdidad en la lengua española, pero esto será tan raro, que no me ocurre ejemplo. Aña-

12 Ibidem, pág. 10-11.

${ }^{13}$ Ibidem, pág. 11. 
dir ha sido menester muchas veces: unas, por dar alguna más claridad a la sentencia que otramente quedaría o dura o del todo ininteligible; lo cual, con todo eso, pretendemos haber hecho con tanta templanza, que en ninguna de las versiones que habemos visto (sacada sola la española de Ferrara) haya menos añadiduras de éstas ni más cortas las que hay que en la nuestra, ni más diligencia en haberlas señalado todas de otra letra que la del texto común, para que el lector las conozca todas y tenga libertad para aprovecharse de ellas, si le parecieren ser al proposito, o dejarlas del todo (como a diligencia humana que puede errar o acertar) y seguir el hilo de su texto, si no le cuadraren, porque en ellas a ningún juicio queremos ni debemos perjudicar" ${ }^{\prime 14}$

Casiodoro de Reina justifica ampliamente en la Introducción el uso que ha hecho de palabras adicionales al traducir el hebreo, buscando por una parte- hacer el texto español inteligible, tal como lo hace con las palabras Señor (en lugar de Jehová) y Concierto (en lugar de Testamento); $y$, por otra, recurriendo a neologismos como reptil, esculptil y esculptura, por no encontrar otra palabras equivalentes en castellano. Las adiciones de palabras las realiza Casiodoro de Reina, principalmente, en los libros en los que no hay texto hebreo, algunos libros del Antiguo Testamento (Job, algunos Salmos y algunos libros de Salomón), y fundamentalmente en el Nuevo Testamento.

Hay algo en la tarea traductora de Casiodoro de Reina que refleja un cierto oficio: el uso del artificio de las Anotaciones al texto Sagrado que ha llevado a cabo en la versión de la Biblia, con el fin de evitar su obscuridad y cuyo origen "suele venir, a saber, o de las cosas que se tratan o de las palabras y formas de decir con que se tratan o de ambas partes juntamente ${ }^{\prime \prime 15}$. Este doble carácter de obscuridad que presenta el texto Sagrado requiere también, en opinión de Casiodoro de Reina, un doble tipo de Anotaciones para introducir claridad en el texto. Cuando la obscuridad radica en las cosas, las Anotaciones al respecto presentan su dificultad por la propia naturaleza de aquéllas, ya que en su mayor parte son cosas "celestiales, espirituales, de naturaleza más sublime de lo que el hombre carnal y su razón puede alcanzar, como el Apóstol $(1$ Cor 1,14) enseña diciendo que ellas son espirituales y él es animal, y de ahí viene que no las perciba, antes la juzgue ser locura

14 Ibidem, pág. 11.

${ }^{15}$ Ibidem, pág. 17. 

las Anotaciones pertinentes que permitan la inteligencia de las mis. mas, sin la cual "es imposible que ninguna claridad de palabras pueda de veras servir" ${ }^{17}$. Sin inteligencia de las cosas, no puede existir clari.
dad en las palabras.

Cuando, por el contrario, la obscuridad proceda de las palabras y de las formas de decirlas, el cometido de las Anotaciones, piensa $\mathrm{Ca}_{\mathrm{a}}$. siodoro de Reina, será conseguir la claridad en las mismas, sin que ello afecte a la integridad del texto original:

"Para remedio de la dificultad que consiste en solas las palabras, procuramos en nuestra versión toda la claridad que nos fue posible, mas de tal manera que el texto quedase siempre en su enterez reteniendo todas las formas de hablar hebraicas que o conciertan con las españolas, como son por la mayor parte, o a lo menos que pueden ser fácilmente entendidas, aunque en ello pecásemos algo contra la pulideza de la lengua española, teniendo por menor mal pecar contra ella, aunque fuese en mucho, que en muy poco contra la integridad del texto" ${ }^{18}$.

No cabe duda que Casiodoro de Reina con sus Anotaciones en la version de la Biblia, hizo una significativa contribución al oficio de traductor, independientemente de los logros conseguidos.

Amén de las Anotaciones, Casiodoro de Reina también incorpora en la versión del texto Sagrado otro artificio, Sumarios de los capítulos, con la finalidad de ayudar al lector a la inteligencia del texto:

“Cuanto a los sumarios de los capítulos, advertirá el lector que no pretendimos tanto hacer sumarios que se quedasen siempre por leer, como argumentos que sirviesen para la inteligencia del capítulo y las más de las veces toda la disposición de él y la conexión de las sentencias, cosa que, como no nos costó poco trabajo, no se hallará en todos comentarios; de donde no es de maravillar si aquellos donde hicimos semejante diligencia nos salieron al parecer un poco prolijos" 1 .

${ }^{16} \mathrm{Ibidem}$, pág. 18.

${ }^{17}$ Ibidem, pág. 17-18.

${ }^{18} \mathrm{Ibidem}$, pág. 18.

${ }^{19}$ Ibidem, pág. 19. 
No cabe duda que este artificio, por su carácter didáctico, facilita, por una parte, la lectura de aquellos textos dotados de Sumarios y la comprension de los mismos y, por otra, constituye una aportación al arte de la traducción.

Casiodoro de Reina acaba la exposición de las anteriores razones 0 criterios mencionados que han sido las lineas directrices que han guiado su tarea de traslación del texto Sagrado, señalando -tal como muestra el siguiente fragmento- que ha sido un trabajo atrevido, no exento de posibles errores y que difícilmente será del gusto de todos. En cualquier caso, Casiodoro de Reina confiesa que el trabajo de version que ha durado doce años, lo ha hecho con toda la fidelidad que ha podido; que no le otorga carácter de infabilidad y, por tanto, se puede corregir, añadiendo y quitando. Igualmente señala su capacidad para haber llevado a cabo el trabajo de traslación, aunque es consciente de que no es perfecto, al presentar sin duda errores.

"Esto es lo más importante de lo que al presente nos pareció que debíamos dar razón de nuestra versión a la Iglesia del Señor, por el bien y consuelo de la cual habemos trabajado [...] Primeramente, en que, habiendo hecho con toda fidelidad todo lo que habemos podido, ningun sano juicio nos reñirá por lo que nuestras fuerzas no alcanzaron [...] Segundamente, en que tampoco pretendemos poner reglas a la Iglesia, la cual de necesidad haya de graduar y canonizar por infalible (digo cuanto es de nuestra versión) [...] Terceramente, en que (para quien nos quisiere corregir con caridad) por la gracia de Dios no somos del número de los que o con razón o sin ella presumen tanto de sí, que tengan por tan acabado lo que una vez sale de sus manos, que nada se le pueda añadir ni quitar [...] La erudición y noticias de las lenguas, aunque no ha sido ni es la que quisiéramos, ha sido la que basta para (como ya arriba hemos tocado) entender los pareceres de los que más entienden y conferirlos entre sí para poder escoger lo más conveniente conforme al sentido y noticias que Dios nos ha dado de su Palabra. Habémosno ayudado del juicio y doctrina ansí de los vivos como de los muertos, que en la obra nos han podido dar alguna ayuda, consultando las más versiones que hasta ahora hay y muchas veces los comentarios [...] Con todo eso no entendemos que lo habemos alcanzado todo: porque, si aun con nuestra cortedad de vista habemos visto y hallado faltas, y algunas no livianas, en los que nos hacen ventaja sin comparación ansí en erudición como en espíritu, no hay por qué no creamos que en nuestra obra aún se hallarán muchas; aunque estamos 

ciertos que ninguna será tal, que por ella merezcamos en juicio sano el
título de corrompedores de la Escritura"20.

Finalmente, Casiodoro de Reina acaba la Introducción afirmando, tal como indica el siguiente fragmento, que la versión de la Biblia que ha realizado es una buena obra en sí misma por tratarse de la palabra de Dios; que es también una obra útil, necesaria a la Iglesia y deseada por los creyentes. Aparte de los errores que pueda contener, Casiodo. ro de Reina señala que su obra es una contribución singular a la len. gua española y cuyo uso de la Sagrada Escritura en lengua vulgar permitirá que todos los hombres tengan acceso a la palabra de Dios.

"Ansí que por poner ya fin a esta nuestra amonestación, la obra que al presente damos, por ser la palabra de Dios y su ley buena en sí y útil y aun necesaria a la Iglesia sin ninguna contradicción, buena es en sí, útil y aun necesaria a la Iglesia y harto deseada de los píos. Por las faltas que en ella hubiere de nuestra parte (las cuales no negamos, aunque no las sabemos) nadie la debe menospreciar, mucho menos calumniar (excepto Satanás, cuyo oficio es o abiertamente o con santos pretextos calumniar lo bueno y estorbar todo lo que en el mundo puede adelantar la gloria de Dios y la salud de los hombres) mayormente, pues que ni hasta ahora hay quien en español haya dado cosa mejor, y ni pudimos más ni estorbamos a quien más pudiere ni queremos poner versión de suma autoridad a la Iglesia ni en las faltas que hubieremos hecho queremos ser pertinaces defensores de ellas, antes protestamos delante del Señor y de todos sus ángeles que nada pretendemos en ella que no sea a su gloria y a la edificación de su Iglesia [...] Y es que, pues que ya se entiende que el uso de la divina Escritura en lengua vulgar es bien que se conceda (como el Decreto del concilio Tridentino ha determinado), prudencia digna de reyes y pastores cristianos sería poner orden con tiempo en mandar hacer una versión, no a uno ni a pocos, sino a diez o doce hombres escogidos por los más doctos y píos de todas las universidades e iglesias del reino, los cuales con diligencia tal consultasen el texto hebreo en el Viejo Testamento y el griego en el Nuevo y todas las versiones que se pudiesen haber, y de todas sacasen una versión latina que sirviese para las escuelas, y otra vulgar que sirviese para el vulgo"21.

${ }^{20}$ Ibidem, pág. 20-21.

${ }^{21}$ Ibidem, pág. 22-23. 


\subsection{CIPRIANO DE VALERA}

La aportación de Cipriano de Valera a la lengua española se hace, tal como se señalo anteriormente, a través de la revisión que lleva a cabo de la traslación de la Biblia realizada por Casiodoro de Reina. Los criterios o razones que orientan su trabajo de revisión los presenta en la Introducción al mismo que él denomina Exhortación. Al cristiano lector a leer la Sagrada Escritura. En la cual se muestra cuales sean los libros Canónicos, o Sagrada Escritura, y cuales sean los libros Apócrifos.

Como es lógico, el desarrollo de la Exhortación de Cipriano de Valera es muy cercano a la Amonestación de Casiodoro de Reina, por la simple razón de que el trabajo del primero es una revisión del segundo, sin que ambos textos difieran en mucho. En el conjunto de la Exhortación de Cipriano de Valera se aboga, como bien señala González Ruiz, "por la necesidad de tener Biblias en lenguas vernáculas, de suerte que el público no sea privado de la Palabra de Dios" (González Ruiz, 1987: XXVII).

En la primera parte de la Exhortación, Cipriano de Valera nos recuerda el mandato de Dios de leer, meditar, escudriñar y rumiar la Sagrada Escritura como medio de salvación y de conocimiento de la verdad: "Pregunto yo ahora: Cómo guardará, o el viejo, o el mozo la palabra de Dios, o cómo les será lumbre en sus caminos, cuando no la conocen, ni saben qué cosa sea cuando no la leen, ni la oyen a otros leer, cuando no la rumian, ni meditan, ni invocan al Señor que les alumbre sus entendimientos para entenderla?" ${ }^{22}$. Dicho mandato divino de leer la Escritura, fue secundado en el tiempo -en opinión de Cipriano de Valera- por los Doctores y concilios antiguos, citando expresamente a S. Juan Crisóstomo quien: "admirablemente exhorta en muy muchos lugares a todo género y fuerte así de hombres como

\footnotetext{
22 Valera, C. (1602): la Biblia. Que es, Los Sacros libros del Viejo y Nuevo Testamento. Amsterdam: Casa de Lorenzo Iacobi, p. 2. En esta cita y en el resto de citas del texto de la Exhortación de Cipriano de Valera la ortografía y las formas gramaticales se mantienen lo más fieles al texto original. Los cambios producidos solo obedecen a facilitar la lectura del texto, pero sin alterarse el contenido del mismo.
} 
de mujeres de cualquier ciudad y condición que sean, chicos, o grandes: ricos, o pobres: doctos, o indoctos, a leer la Escritura" ${ }^{23}$.

Cipriano de Valera extiende el mandato divino de leer la Biblia a que ésta fuera divulgada en todas las lenguas para el conocimiento de todos, mencionando las diversas versiones vulgares conocidas de la misma, tanto en el mundo cristiano como particularmente en España:

"El mismo Dios, que mando que todos sin hacer diferencia ninguna ni de sexo, ni de edad, ni de cualidad leyesen la sagrada Escritura, este mismo ordeno que ella fuese divulgada en todas lenguas (como vemos que lo es) para que ninguno pretendiese ignorancia. Así en tiempo pa. sado se divulgo en las tres lenguas más principales y más comunes, que entonces se usaban en el mundo: que eran la Hebrea, Griega y Latina. Después los hombres píos y doctos movidos de un santo celo de hacer bien a los de sus naciones, la trasladaron en sus lenguas vulgares $^{24}$.

Además de hacer memoria Cipriano de Valera de anteriores versiones de la Biblia en lengua vulgar española, también tiene interés en mencionar aquellas versiones vulgares de textos bíblicos que le son cercanas y familiares en su tiempo como la Biblia en lengua Valenciana, la Biblia de Ferrara, la de Casiodoro de Reina, el Nuevo Testamento de Francisco de Enzinas, etc., pero sin olvidar aquellas dos admirables Biblias, la Complutense y la Regia, impulsadas por dos eximios españoles, Cardenal Cisneros y Benito Arias Montano, e impresas en diversas lenguas: hebreo, griego y latín, principalmente: "Después acá el mismo Dios movido de la misma misericordia que antes, ha levantado algunos Españoles en nuestros tiempos, que han trasladado los libros sagrados. Los libros impresos en Español que yo he visto, son los siguientes: La Biblia en lengua Valenciana, con licencia de los Inquisidores a cuya traslación asistió $S$. Vicente Ferrer: que ha más de ciento y tantos años se imprimió in folio de papel real. El Testamento viejo fin los libros Apócrifos, impreso año de 1553 en Ferrara palabra por palabra como está en Hebreo, que es un gran tesoro de la lengua Española. La biblia de Casiodoro de Reina impresa en Basilea año de 1569. Francisco de Enzinas Burgalés trasladó año de

${ }^{23}$ Ibidem, pág. 2.

${ }^{24}$ Ibidem, pág. 3. 
$1542 \mathrm{el}$ Testamento nuevo, y lo presento al Emperador don Carlos en Bruselas [...] Demás destas traslaciones en Español, que habemos nombrado, hay dos admirables Biblias impresas en diversas lenguas (como luego diremos) que Españoles han hecho: las cuales son, y con muy gran razón muy estimadas de todos los doctos, de cualquiera nación que sean. La causa porque se hayan imprimido diremos aquí.

En el Concilio Vienense se mandó que las lenguas, Latina, Griega, Hebrea, Caldea y Arábiga se leyesen públicamente en las universidades. Conforme a este Decreto don Francisco Ximenes fraile Francisco, Arzobispo de Toledo, Cardenal, Governador y Inquisidor general de España, y fundador de la célebre universidad de Alcalá, que en latín se llama Complutum [...], hizo imprimir año de 1515 aquella admirable Biblia.

"Habiéndose distraído todos los ejemplares de la dicha impresión del Cardenal, de tal manera que por ningún dinero no se podían hallar [...], plugo a nuestro Dios, movido de la misma misericordia que antes, inspirar en el corazón de Benito Arias natural de Frexenal de la Sierra (y por ello se llama Montano, al cual yo conocí estudiando en Sevilla, de hacer otra nueva impresión: para que la Iglesia de Dios no careciese de tanto bien: y así vino, no ha muchos años, a Amberes: donde a costa del Rey don Felipe la imprimió poniendo juntamente con el texto Hebreo la versión Caldaica, Griega, Siriaca, y algunas versiones Latinas viejas y nuevas ${ }^{\prime \prime 2}$.

Cipriano de Valera concluye la primera parte de la Exhortación, recordando que la ignorancia en la Sagrada Escritura es causa de las herejías y alimenta el dicho del vulgo cristiano ignorante de que la Biblia en lengua vulgar es un libro maldito y que su lectura es más dañina que la lectura de los libros de los filósofos paganos:

"Porque el ignorar la Escritura causa las herejías [...], los que nunca leen la Escritura Sagrada, ni saben qué cosa es? Hablo del vulgo ignorante, que se llama Cristiano: los cuales engañados de sus falsos profetas, creen y así lo dicen la Biblia ser un libro maldito y descomulgado, lleno de heregías [...] Que mucho mayor daño causa la Lección de la

${ }^{25} \mathrm{Ibidem}$, pág. 3. El texto se refiere a la llamada Biblia Políglota de Amberes y conocida como Biblia Regia.

Futhark 9 (2014)

Monreal, Biblismo, lengua vernácula y traducción, 337-371

ISSN $1886-9300$ 
sagrada Escritura en lengua vulgar, que leer los libros de los filosofos paganos, $y$ que por ello se prohibe lo primero, $y$ no lo segundo"26.

En la segunda parte de la Exhortación, Cipriano de Valera expone diferentes cuestiones relacionadas con la revisión y publicación que lleva a cabo de la Biblia de Casiodoro de Reina. En primer lugar, nos dice que el motivo por el que ha hecho la revisión del texto de Casio. doro de Reina ha sido simplemente por haberse agotado la primera edición y considerar necesario una segunda edición de la misma por ser un gran tesoro en la lengua española:

"Resta ahora dar cuenta que nos haya movido a hacer esta segunda Edición. Casiodoro de Reina movido de un pío celo de adelantar la gloria de Dios, y de hacer un señalado servicio a su nación, en viendo se en tierra de libertad para hablar y tratar de las cosas de Dios, comenzo a darse a la traslación de la Biblia. La cual tradujo; y así año de 1569 imprimió dos mil y seiscientos ejemplares: Los cuales por la misericordia de Dios se han repartido por muchas regiones. De tal manera que hoy casi no se hallan ejemplares, si alguno los quiere comprar. Para que nuestra nación Española no careciese de un tan gran tesoro, como es la Biblia en su lengua, habemos tomado la pena de leerla y releerla una y muchas veces, y la habemos enriquecido con nueva notas y aun algunas veces habemos alterado el texto" ${ }^{\prime 27}$.

En segundo lugar, Cipriano de Valera explica cómo ha realizado la revisión de la segunda edición de la Biblia de Casiodoro de Reina trabajo realizado lo lleva a cabo, siguiendo a Casiodoro de Reina, contrastándolo con la opinión: ha incorporado nuevas notas y ha alterado también el texto. Ahora, este de los doctos y píos y con otras traslaciones de los textos Sagrados existentes en otras lenguas. Seguramente, la satisfacción que le produce esta metodología seguida, le lleva a valorar su nueva edición como trabajo excelente, no solo a juicio suyo sino también de los entendidos en la materia:

"La cual habemos hecho con maduro consejo y deliberación: y no fiando nos de nosotros mismos (porque nuestra consciencia nos restifica cuan pequeño sea nuestro caudal) lo habemos conferido con hombres doctos y pios, y con diversas traslaciones, que por la misericordia de

${ }^{26}$ Ibidem, pág. 4.

${ }^{27}$ Ibidem, pág. 6. 
Dios hay en lenguas diversas el día de hoy. Cuanto a lo demás, la versiôn, conforme a mi juicio, y al juicio de todos los que la entienden, es excelente ${ }^{\text {m28 }}$.

En tercer lugar, Cipriano de Valera señala que el criterio que ha seguido en la traslación ha sido palabra por palabra, pero advirtiendo que esta regla traductora se ha materializado cuando ha sido posible. Por tanto, la traducción literal ha sido el criterio general utilizado, pero aplicado con flexibilidad. También en este aspecto, Cipriano de Valera ha continuado la forma de traslación de Casiodoro de Reina: "y así habemos seguido, cuanto habemos podido, palabra por palabra" 29 . La aplicación de la literalidad con flexibilidad explica que Cipriano de Valera proponga, por una parte, la supresión de determinadas palabras por considerarlas no convenientes o porque no responden al texto hebreo; y por otra, también utiliza el recurso de añadir notas de texto (con determinadas señales) para una adecuada interpretación de las palabras vertidas.

Finalmente, Cipriano de Valera acaba su Exhortación recordando al futuro lector que la nueva versión de la Biblia de Casiodoro de Reina es el fruto de mucho trabajo, realizado durante largo tiempo (20 años), hecho en solitario y sin apenas ayuda, e impreso gracias a la ayuda de pía gente. Por ello, reclama una buena aceptación de la segunda edición de la Biblia en la lengua Española:

"El trabajo, que yo he tomado para sacar a luz esta obra, ha sido muy grande, y de muy largo tiempo: y tanto ha sido mayor, cuanto yo he tenido menos ayuda de alguno de mi nación que me ayudase, siquiera a leer, escribir, o corregir. Todo lo he hecho yo solo [...] Yo siendo de 50 años comencé esta obra: y en este año de 1602 en el que ha placido a mi Dios sacarla a luz, soy de 70 años (edad es esta en que las fuerzas desfallecen, la memoria se entorpece y los ojos se oscurecen). De manera que he empleado 20 años en ella. Todo el cual trabajo doy por muy bien empleado [...] Esta Biblia fue imprimida con la ayuda y asistencia de pía gente. He dicho esto para que su memoria sea eterna: y para que otros a su ejemplo se ocupen en semejantes obras de piedad [...] Por tanto hermanos míos muy amados, exhortamos os en el nombre del Señor, cuyos embajadores somos, que no recibáis en vano la gracia que

${ }^{28} \mathrm{Ibidem}$, pág. 6.

${ }^{29} \mathrm{Ibidem}$, pág. 6.

Futhark 9 (2014) Monreal, Biblismo, lengua vernácula y traducción, 337-371 ISSN 1886-9300 
su Majestad os hace de manifestaros su voluntad hablando os hoy en
vuestra lengua Espantola" 30 .

\section{REFERENCIAS BIBLIOGRÁFICAS}

ABELLÁN, J.L.; El Erasmismo español, Madrid, Espasa-Calpe, 1982.

ABELLÁN, J.L., "La difusión del erasmismo desde el ámbito complutense", en MORENO, Luis Jiménez (coord.), La Universidad Complutense Cisneriana, Madrid, Editorial Complutense, 1996, págs. 107-112.

ALONSO SCHÖKEL, Luis, "La Biblia de Alfonso el Sabio", en: Cuadernos Biblicos,
10, 1984, págs. 67-78.

ANDRES, M.; La teología española en el siglo XVI, Vol. I, Madrid, Biblioteca de Autores Cristianos (B.A.C.), 1976.

Batallon, M.; Erasmo y España, México, Fondo de Cultura Económica, 1986.

BERGER, S., "Les Bibles castellanes", en: Revue Romania, 28, 1989, págs. 360-408.

CARRERA, A.; El 'problema de la lengua', en el Humanismo renacentista español, Universidad de Valladolid, Secretariado de Publicaciones, 1988.

ERASMO De ROTTERDAM; Obras escogidas, Edición de Lorenzo Riber, Madrid, Aguilar, 1964.

FEBVRE, L; Erasmo, la Contrarreforma y el espíitu moderno, Barcelona, Martínez Roca, 1970.

FERNÁNDEZ, E.; Las Biblias castellanas del exilio: historia de las Biblias castellanas del siglo XVI, Universidad de Californa, Editorial Caribe, 1976.

FERNÁNDEZ, N. y Fernández E.; Biblia y humanismo, Madrid, Fundación Uni. versitaria Española, 1997.

GarCia ORO, J.; El Cardenal Cisneros. Vida y empresas. Volumen II, Madrid, Biblioteca de Autores Cristianos (B.A.C), 1992.

Garcí-VIllosladA, R., "El Erasmismo español", en Historia General de las Literaturas Hispánicas, vol. II, Barcelona, Editorial Vergara, 1968, págs. 359. 383.

GONZALEZ RUIZ, J.M., "Introducción General a la Biblia del Oso", en: Casiodoro de Reina: La Biblia del Oso. Según la traducción de Casiodoro de Reina publicada en Basilea en el año 1569, Edición de Juan Guillén Torralba, Madrid, Alfaguara, 1987.

HAUBEN, P.J.; Del monasterio al ministerio: tres herejes españoles y la reforma, Madrid, Editora Nacional, 1978.

KINDER, A.G.; Casiodoro de Reina, London, Tamesis Books Limited, 1975.

${ }^{30} \mathrm{Ibidem}$, pág. 7.

Futhark 9 (2014)

ISSN $1886-9300$

Monreal, Biblismo, lengua vernácula y traducción, 337-371 
LAZAR, M., "De la Biblia romanceada serfardí del siglo XII a la Biblia de Ferrara (1553): su contribución a la lengua y a la Biblia españolas", en: La herencin espaniola en el pensamiento sefardi, Curso en la Universidad Internacional Menéndez Pelayo, Santander 5-9 Agosto, 1991.

MENÉNDEZ Pelayo, M.; Historia de los heterodoxos españoles. Vol. IV. Madrid, Consejo Superior de Investigaciones Científicas (C.S.I.C.), 1947.

MONREAL, J. L., "La perspectiva religiosa y el uso de la lengua en Lutero", en: Revista Futhark, 7, 2012, págs. 189-228.

MORREALE, M., "Apuntes bibliográficos para la iniciación al estudio de las traducciones bíblicas medievales al castellano", en: Sefarad, 20, 1960, págs. 66-109.

- "Vernacular Scriptures in Spain", en: LAMPE, G.W.H.: The Cambridge History of the Bible, II. Cambridge, Cambridge University Press, 1963a, págs. 465-491.

- "Spanish Versions", en: LAMPE, G.W.H.: The Cambridge History of the Bible, III. Cambridge, Cambridge University Press, 1963b, págs. 125-129.

ReINA, C. de; La Biblia del Oso. Según la traducción de Casiodoro de Reina publicada en Basilea en el año 1569, Edición de Juan Guillén Torralba, Madrid, Alfaguara, 1987.

SÁNCHEZ- PRIETO, P. et al.; Alfonso X Rey de Castilla. General Estoria. $1^{\text {a }}$ Parte-5 ${ }^{\mathrm{a}}$ Parte, Madrid, Fundación José Antonio de Castro, 2009.

SEPHIHA, H.V.; Le ladino judéo-espagnol calque. Deutéronome. Versions de Constantinople (1547) et de Ferrare (1553), Paris, Edition, étude linguistique et lexique, 1973.

VALERA, C. de; La Biblia. Que es, Los sacros libros del Viejo y Nuevo Testamento, Amsterdan, Casa de Lorenzo Iacobi, Edición de la Biblioteca Nacional de España, 1602. 